\title{
Operationalising a resilience approach to adapting an urban delta to uncertain climate changes
}

\author{
J. Arjan Wardekker ${ }^{\mathrm{a}, *}$, Arie de Jong ${ }^{\mathrm{a}}$, Joost M. Knoop ${ }^{\mathrm{b}}$, Jeroen P. van der Sluijs ${ }^{\mathrm{a}, \mathrm{c}}$ \\ a Department of Science, Technology and Society, Copernicus Institute for Sustainable Development and Innovation, Utrecht University, \\ Heidelberglaan 2, 3584 CS Utrecht, The Netherlands \\ b Netherlands Environmental Assessment Agency (PBL), P.O. Box 303, 3720 AH Bilthoven, The Netherlands \\ ' Centre for Economics and Ethics of the Environment and Development, University of Versailles Saint-Quentin-en-Yvelines, 47 Boulevard Vauban, \\ Guyancourt 78047 cedex, France
}

\section{A R T I C L E I N F O}

\section{Article history:}

Received 15 April 2009

Received in revised form 2 November 2009

Accepted 10 November 2009

\section{Keywords:}

Resilience

Resilience principles

Climate change adaptation

Uncertainty

Urban planning

\begin{abstract}
A B S T R A C T
Climate change may pose considerable challenges to coastal cities, particularly in low-lying urban deltas. Impacts are, however, associated with substantial uncertainties. This paper studies an uncertainty-robust adaptation strategy: strengthening the resilience of the impacted system. This approach is operationalised for the city of Rotterdam, using literature study, interviews, and a workshop. Potential impacts have been explored using national climate statistics and scenarios and a set of 'wildcards' (imaginable surprises). Sea level rise, particularly in combination with storm surge, and enduring heat and drought are the most relevant potential stresses in the area. These can lead to damage, loss of image, and societal disruption. Unclear responsibilities enhance disruption. 'Resilience principles' made the concept of resilience sufficiently operational for local actors to explore policy options. Useful principles for urban resilience include: homeostasis, omnivory, high flux, flatness, buffering, redundancy, foresight and preparedness/planning, compartmentalisation, and flexible planning/design. A resilience approach makes the system less prone to disturbances, enables quick and flexible responses, and is better capable of dealing with surprises than traditional predictive approaches. Local actors frame resilience as a flexible approach to adaptation that would be more suitable and tailored to local situations than rigid top-down regulations. In addition to a change in policy, it would require a more pro-active mentality among the population.
\end{abstract}

(c) 2009 Elsevier Inc. All rights reserved.

\section{Introduction}

The expected impacts of climate change may pose considerable challenges to coastal cities, particularly to those in low-lying deltas [1]. Changes in sea level, river discharge and weather extremes, combined with increasing potential impacts due to population growth and increasing value of capital, enhance the need to make cities 'climate-proof. Irrespective of mitigation efforts, some degree of climate change is inevitable, and adaptation will be necessary [2,3]. Projections of climate change, however, are plagued by substantial uncertainties, particularly when translated into local impacts [4]. For decision makers, it is not always easy or straightforward on how to interpret and use climate scenarios and uncertainty information, and how to appraise the policy implications of uncertainties [5,6]. In literature, various approaches for dealing with uncertainty are formulated for climate change adaptation [4,7]. Examples include: risk approach, anticipating design, resilience, adaptive management, and robust decision making. This paper presents a case-study on a system-oriented strategy: strengthening the resilience of the impacted system to climatic changes.

\footnotetext{
* Corresponding author. Tel.: +31 30 2533618; fax: +31 302537601

E-mail address: J.A.Wardekker@uu.nl (J.A. Wardekker).
} 
A central question in this paper is: what could a resilience approach to climate change adaptation entail for an urban delta? The paper aims to operationalise the concept of resilience. This is examined for the municipal areas outside the dike defence zones in Rotterdam, The Netherlands. This flood-prone, densely populated, and economically important region faces numerous climate adaptation challenges. Additionally, major municipal restructuring is planned, which allowed for free exploration of new adaptation concepts, rather than having to work within the limits of an existing situation.

The concept of resilience emerged from ecology in the 1960s and early 1970s [8,9]. It has since been adopted by various disciplines and in interdisciplinary work, using diverging definitions ranging from a narrow technical term to an umbrella concept and metaphor [9-12]. Folke [9] identifies a sequence of resilience concepts, from narrow to broad: (1) engineering resilience, (2) ecosystem resilience and social resilience, and (3) social-ecological resilience. The first two focus on recovery rate and withstanding shock respectively. The last focuses on the interplay between disturbance and reorganization. In the literature on resilience, the concept is currently defined as "the capacity of a system to absorb disturbance and reorganise while undergoing change so as to still retain essentially the same function, structure, identity, and feedbacks" [13]. Three characteristics of (socialecological) resilience are identified [11,14]:

1. The amount of change the system can undergo and still retain the same controls on function and structure.

2. The degree to which the system is capable of self-(re)organization to accommodate external changes.

3. The ability to build and increase the capacity for learning and adaptation. ${ }^{1}$

This relatively broad definition seems suitable for the topic of climate change adaptation in urban deltas that face not only disturbing events (shocks; e.g. floods), but also disturbing trends (e.g. sea level rise). On longer timescales, withstanding and recovering from singular disturbing events is insufficient. A resilient system should also encompass the dynamics to accommodate trends and co-evolve; to 'bounce back in better shape' $[15,16]$. While umbrella concepts and metaphors are useful inspirational tools, and while using an overly narrow definition could restrict policymakers involved, resilience needs to be made operational to develop policies that increase it. Several studies propose resilience indicators for specific subsystems, aiming to provide a basis for quantitative evaluation of possible policy strategies (e.g. [10,11,17-19]). Other studies, such as the present paper, qualitatively explore policy options and strategies that could enhance a system's resilience (e.g. [20] on urban adaptation strategies in the Greater Vancouver region, Canada). The operational definition of a resilient system used in this study is: "a system that can tolerate disturbances (events and trends) through characteristics or measures that limit their impacts, by reducing or counteracting the damage and disruption, and allow the system to respond, recover, and adapt quickly to such disturbances". In this definition, tolerating disturbances is taken in contrast to resisting these (e.g. by building dikes).

This paper considers a 'resilience approach' a 'bottom-up' way of thinking about adaptation that aims to promote a system's capability of coping with disturbances and surprises, based on the concept of 'resilience'. This is very different from the predictand-prevent approaches that are traditional in Dutch water management. ${ }^{2}$ Similar to the Vancouver study [20], we assessed trends/impacts, defined characteristics that make a system resilient, and used these to explore options and to specify and categorise how they can contribute to the system's resilience. These characteristics were intended to support 'resilience-thinking'. The Vancouver study uses a set of ad-hoc ideas on what a resilient urban system implies. This study used six 'resilience principles' from ecological and system dynamics literature [4,15,23], and tested their usability for supporting resilience-thinking in relation to urban adaptation:

- Homeostasis: multiple feedback loops counteract disturbances and stabilise the system.

- Omnivory: vulnerability is reduced by diversification of resources and means.

- High flux: a fast rate of movement of resources through the system ensures fast mobilization of these resources to cope with perturbations.

- Flatness: the hierarchical levels relative to the base should not be top-heavy. Overly hierarchical systems with no local formal competence to act are too inflexible and too slow to cope with surprise and to rapidly implement non-standard highly local responses.

- Buffering: essential capacities are over-dimensioned such that critical thresholds in capacities are less likely to be crossed.

- Redundancy: overlapping functions; if one fails, others can take over.

\section{Research design}

The region studied included the municipal areas outside the dike defence zones in Rotterdam, plus the river, surge barrier, connections, and outside service generation (Section 3). The study consisted of two parts: vulnerability assessment and options generation. Three methods were used: literature review, interviews [24], and a workshop [25]. For the vulnerability assessment, trends were deduced from literature, but information from local practitioners (interviews/workshop plus local policy documents) was critical in exploring the local implications. Options generation required interactive discussion and was based primarily on the workshop. Interviews and local documents provided information on current plans.

\footnotetext{
1 This paper interprets this characteristic as the meta-capacity to build and enhance adaptive capacity. System characteristics such as flexibility, responsiveness and openness towards change and learning facilitate adaptation, making it faster, easier, more efficient/effective, or otherwise more practical.

2 Prevention-orientation (e.g. prevent flooding and climate change) and promotion-orientation (e.g. promote resilience and sustainability) are psychologically also two fairly different ways to frame goals and behaviour (e.g. [21,22]).
} 


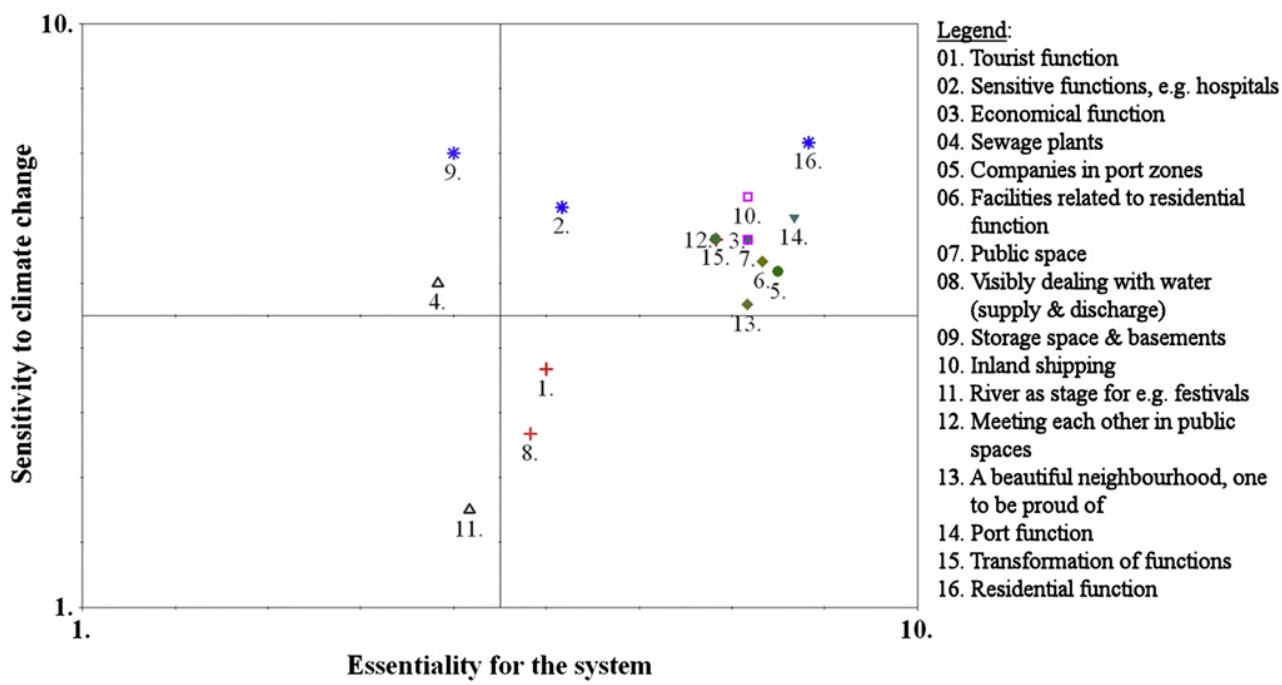

Fig. 1. Example: participant-scoring of 'usage functions' on essentiality and sensitivity. The further top-right, the higher the priority of taking it into account in further discussion.

Scientific literature concerning climate change and concerning resilience was reviewed in order to gain an understanding of possible future disturbances due to climate change, and how resilience could play a role in adaptation. Documents concerning the region, its history, development plans, and local policy practices were analysed in order to gain an understanding of the area and the challenges it faces.

Semi-structured interviews were held with five local and regional practitioners to gain additional insight into the area and its policy practices. Respondents included a city planner, housing expert, legal expert, water engineer, and water and water safety advisor from the Rotterdam Department for Urban Planning and Housing (dS + V), Rotterdam Public Works Department (GW), and the Province of South Holland.

The workshop provided a platform for interaction between local practitioners and scientists from a number of relevant disciplines. Participants included a legal expert, water engineer, landscape architect, and housing expert from the Rotterdam dS + V and GW departments, as well as a social psychologist, climate scientist, policy scientist, and climate adaptation policy expert from four Dutch knowledge institutes.

The workshop aimed to construct an overview of relevant disturbances and promising adaptation options. During a process of 'group model building' [26,27], participants developed a system description (conceptual model) of the area. The 'components' of the system (in four categories: physical conditions, usage functions, facilities, and infrastructure) and possible climate-related problems were inventoried. Participants prioritised/evaluated these for inclusion in the group model ${ }^{3}$ using basic 1-10 scales, indicating the relative magnitude. Components were scored on (a) estimated essentiality for the system and (b) sensitivity to climate change. The higher a component's weighted average, the higher its priority. For an example, see Fig. 1. The top five components in each category are listed in Table 1. Problems were scored based on estimated importance. Brainstorms were facilitated using a group decision support system with GroupSystems software $[29,30]$. The conceptual model was created using Quasta $[31,32]$. The six principles of resilience were used in a brainstorm session to structure the generation of policy options that can increase resilience of the area.

\section{Description of the area}

Rotterdam is adjacent to the North Sea and accommodates Europe's largest seaport. A branch of the river Rhine, the Nieuwe Maas (eastern part) and Nieuwe Waterweg (western part), flows through the city into the North Sea. The study area included the areas outside the dike defence zones in the centre of Rotterdam, about $16 \mathrm{~km}^{2}$ in size. In addition to this focus area, several other parts of Rotterdam that are critical to the area's functioning were taken into account: the river, downstream Maeslantkering storm surge barrier, connections (e.g. roads and pipes), and outside service generation (e.g. water and electricity).

Even today, the area has a port function, combined with a small scale residential function. The current average ground level of the study area is approximately $+3.25 \mathrm{~m}$ above NAP. ${ }^{4}$ However, some parts have a ground level of approximately $+2.50 \mathrm{~m}$ NAP and others of $+5.00 \mathrm{~m}$ NAP. Parts of the area experience limited flooding up to twice per year.

The local government recently decided to redevelop the area. In the 'city vision' for 2030 [33], the municipality voices the goal "to establish a strong economy and an attractive city". Partly, this objective should be achieved in the areas outside the dike

\footnotetext{
3 This process of collecting individual input and prioritizing/ranking to select the most important ideas is referred to as Nominal Group Technique [28].

${ }^{4}$ NAP (Normaal Amsterdams Peil; Amsterdam Ordnance Datum) is the standard Dutch reference height compared to mean local sea level.
} 
Table 1

Critical components of the area (top five per component type, rated by workshop participants based on importance for the area and sensitivity to climate change).

\begin{tabular}{|c|c|c|c|}
\hline Physical conditions & Usage functions & Facilities $^{\mathrm{a}}$ & Infrastructure $^{a}$ \\
\hline $\begin{array}{l}\text { Ground subsidence (may be equal to } \\
\text { sea level rise) }\end{array}$ & $\begin{array}{l}\text { Economical functions } \\
\text { (probably mainly services) }\end{array}$ & (Para)medical facilities & Electricity \\
\hline $\begin{array}{l}\text { Water system (water comes from east, west, } \\
\text { above, below; sometimes all at once) }\end{array}$ & $\begin{array}{l}\text { Public spaces (green areas, } \\
\text { roads) }\end{array}$ & Cooling & Sewage system \\
\hline Tidal differences & Inland shipping & Energy supply & Main roads leading in/out of the area \\
\hline $\begin{array}{l}\text { Water barriers (which are an obstacle, both } \\
\text { physical and social, towards the hinterland) }\end{array}$ & Port functions & Drinking water & Main water barriers \\
\hline Local ecology & Residential functions & Disaster management organization & Maeslantkering storm surge barrier \\
\hline
\end{tabular}

${ }^{a}$ Note that some things are included in both facilities and infrastructure. E.g. for drinking water supply: availability of drinking water (facility) and pipes (infrastructure). The latter did not make the top-5.

defence zones, by transforming these into urban residential and working areas. From 2013 onwards, most of the port activities will be translocated to new land extending into the North Sea (the 'Tweede Maasvlakte'). One part of the old port area, the 'Waal- and Eemhaven', will retain its port function and was not taken into account in this study. In the remaining part, until 2025, approximately 7000-10,000 houses will be built, as well as offices and other commercial buildings. Foreseen functions for the urban area under redevelopment include: living, working, recreation, cultural functions, and tourism. The area intends to host a wide range of facilities and will include various types of infrastructure (see Table 1).

\section{Climate change related problems for the area}

This section will describe the disturbances and policy challenges that the area may come to face due to climate change.

\subsection{Temperature}

The 'KNMI'06' climate scenarios for the Netherlands [34-36] project summer temperature changes of $+1.7-5.6{ }^{\circ} \mathrm{C}$ in 2100 (compared to 1990). Relevant effects include a likely increase in the number of warm days, more heat waves, and reduced air quality $[1,34]$. Drought during extended warm periods may result in local problems. River water, which is used to cool power plants, may become too warm and in short supply, forcing energy companies to reduce production. Water supply for consumers and companies may be limited, while demand increases. Heat-related health effects would be limited due to the area's open character and close proximity to the river. Warm periods could also be beneficial, providing recreational opportunities for the water-rich area.

\subsection{Sea level rise}

The KNMI'06 scenarios project a local sea level rise of $+0.35-0.85 \mathrm{~m}$ in 2100 [34-36] excluding ground level subsidence $(0.10 \mathrm{~m} /$ century $)$. Considering local ground levels $(+2.50-5.00 \mathrm{~m} ;+3.25 \mathrm{~m}$ average $)$, many parts of the area experience regular flooding (Table 2). Projected sea level rise will increase flooding risks. The Maeslantkering closes at a projected water level of $+3.00 \mathrm{~m}$ (city centre), limiting water levels for the area. Above that level, flooding depends mainly on the Maeslantkering's failure probability $(1 / 100$ per order to close [37,38]). Sea level rise would increase closure frequency and could reduce the barrier's effectiveness in limiting city water levels [39].

Table 2

Current exceedance frequencies of local water levels in Rotterdam [40].

\begin{tabular}{lll}
\hline $\begin{array}{l}\text { Frequency } \\
\text { (times/year) }\end{array}$ & Water level (m above NAP) & \\
\cline { 2 - 3 } & Coast (Hoek van Holland) & City centre (includes Maeslantkering and its failure probability) \\
\hline $1 / 10000$ & 5.05 & 3.58 \\
$1 / 4000$ & 4.30 & 3.51 \\
$1 / 1000$ & 3.60 & 3.42 (large majority flooded) \\
$1 / 100$ & 3.40 & 3.26 (majority flooded) \\
$1 / 50$ & 3.15 & \\
$1 / 20$ & 3.00 & 2.99 (flooding in large parts) \\
$1 / 10$ & 2.80 & \\
$1 / 5$ & 2.60 & 2.68 \\
$1 / 2$ & 2.45 & 2.56 (flooding in small parts) \\
1 & 2.30 & \\
2 & 2.10 & \\
5
\end{tabular}


Local actors perceived sea level rise and flooding as the most prominent issue for the area. ${ }^{5}$ Floods could result in damage, societal disruption, and damage to the area's image, reducing its attractiveness for residents and investors. The appearance of not being adequately prepared for climate change may also lead to stigmatisation. Companies may be concerned about the long-term viability of the area for their activities. Other challenges included: spatial claims for future flood prevention, environmental catastrophes in the port areas, traffic disruption due to flooded roads and tunnels, flooded basements and parking garages, and possible plunder during evacuations.

\subsection{Wind and windstorms}

Projected changes in wind speed are relatively small compared to natural interannual variation and long-term fluctuations. The strength of the heaviest storms is also projected to increase slightly. However, projections for extreme wind direction, particularly for northwest (relevant for storm surge), are ambiguous [35]. Local wind-related problems are not expected, but storm surge is important for flood risks. Changes in surge level of $+0.1-0.25 \mathrm{~m}$ are projected due to storminess (1/50 frequency; 2080) [41, Fig. 2]. Additionally, port activities may need to be halted during heavy storms.

\subsection{River discharge}

Expected increases in winter precipitation, and upstream rainfall rather than snowfall, can lead to increased peak discharge. This should not be a problem, as local river levels are determined primarily by the sea level [42]. In combination with sea level rise and storm, it is however relevant for decisions concerning the closing-regime of the Maeslantkering. When this barrier is closed, local river water accumulates. Increased discharge implies that more capacity is needed to temporarily retain river water. Summer discharge is expected to decrease. Low river levels could hamper inland shipping. Water pollutant concentrations and salinisation could increase. Salinisation has consequences for local ecology and drinking water supply.

\subsection{Precipitation extremes}

Precipitation amounts on extremely wet days are projected to increase in the KNMI'06 scenarios. This could result in flooding when the capacity of the sewer system is exceeded. However, this is unlikely as the area is elevated above sea level, with a groundwater level of $-1 \mathrm{~m}$, and has many options for drainage.

\subsection{Societal and governmental issues}

The main adaptation-related societal issue was that of unclear responsibilities. Formally, residents who choose to live in areas outside the dike defence zones do so at their own risk; they are assumed to take this risk knowingly and willingly. However, residents perceive the government to be responsible for flood protection, and the exact legal responsibilities for property damage are unclear. Additionally, (new) residents may lack awareness of the risks of living in such an area. They are not actively informed, since no party is responsible for doing so. Furthermore, flood management protocols are absent. Current policies for flood protection in areas outside the dikes are also being changed, and the outcome of this process is unknown. This 'legal uncertainty' could make the area less attractive and enhance societal disruption after floods. Unclear responsibilities thus function as a feedback that worsens impacts.

Another issue is the conflicting interests of various policy fields. The area faces many other developments that call for adaptation. For the greater Randstad metropolitan area, urbanisation and housing, economic development, and mobility/ accessibility pose significant challenges with uncertain spatial claims $[43,44]$. Uncoordinated communication by various governmental units results in 'information overload'. Governmental anticipation on changes is slow, and public support for adaptation policy is lacking due to low participation.

\subsection{Wildcards}

A set of area-relevant 'wildcards' has been developed ${ }^{6}$ to reflect on whether strategies can cope with surprises. They describe events with unknown or low probabilities and possibly large consequences.

\subsubsection{Rapid ice-sheet melting}

Rapid melting will strongly increase sea level rise. The Delta committee [45] proposes an upper-bound scenario of $+0.65-$ $1.30 \mathrm{~m}$ in 2100, including subsidence. MNP [46] posits a worst case of $+1.50 \mathrm{~m} /$ century.

\footnotetext{
${ }^{5}$ From a resilience point-of-view, this local framing of the adaptation challenge as a water issue may be a shortcoming; a broader palette of relevant disturbances should be taken into account. In addition, storm surge may be more important for flooding risks than sea level rise.

${ }^{6}$ The wildcards were included in the handout for use during the workshop's options-brainstorms.
} 


\subsubsection{Collapse of the thermohaline circulation (THC)}

The implications of a shutdown of the ocean circulation are very uncertain. Relevant potential impacts include: reduced yearlyaverage temperature, more severe winters, enhanced summer drying, additional local sea level rise, increased cold-related mortality, and negative impacts on summer tourism (e.g. [47]).

\subsubsection{Frozen port}

Changes in atmospheric and ocean circulation may locally offset global warming such that severe winter freezings cannot be excluded. Non-complete freezing would hamper inland shipping. Complete freezing, such as in 1969, could hamper drinking water supply and ice-drift could damage roads and buildings. Low temperatures pose health risks for elderly and homeless. Combination with 'extreme storm' and 'Maeslantkering failure' could be disastrous.

\subsubsection{Port malaria incidents}

Malaria-infected mosquitoes occasionally board and survive the journey onboard airplanes and, more rarely, ships, and infect people near the airport/seaport (e.g. [48]). Higher temperatures will increase the number of months suitable for transmission. While the healthcare system is well-capable of dealing with malaria, autochthonous cases are likely to be misdiagnosed. Multiple cases could cause public unrest.

\subsubsection{Modified German water safety policy}

Peak river discharge volumes are limited by the capacity of the German water system. Would German water safety policy become significantly stricter, higher peak discharges may pose new challenges to water management in Rotterdam (although the EU flood directive may limit this potential threat).

\subsubsection{Enduring heat and drought}

An extended warm period can cause several problems. (a) Low river water tables and warm water may compromise energy production (insufficient cooling capacity) and drinking water supply. Certain areas might need to be disconnected. (b) Sustained exposure to heat may lead to heat stress and higher electricity demand. Health effects are amplified by high humidity and air pollution. (c) Reduced groundwater levels may lead to subsidence and sagging of buildings.

\subsubsection{Extreme storm}

The area has a very open character and is located close to the sea and above sea level. In the eventuality of an extreme storm, it will be relatively exposed to the wind. This may have implications for future spatial planning and building construction.

\subsubsection{Maeslantkering failure plus extreme storm}

Should an extreme (north-western) storm, coincide with the Maeslantkering failing to close, the consequences may be large. The Municipality explored this scenario: with a water level of $+4.10 \mathrm{~m}$ most of the area will flood [39].

\section{Options for resilience}

This section describes options that could be considered within a resilience approach to climate change adaptation in the area. It aims to illustrate what such an approach could entail; not to provide a complete list of options. Options are discussed per 'resilience principle'.

\subsection{Homeostasis}

Homeostasis involves incorporating feedback loops that stabilise the system to external perturbations. One set of options suggested by participants involved removing the feedback-loop of 'unclear responsibilities' (paragraph 4.6) by establishing clarity on the responsibilities and (financial) liability in case of flooding. Water damage should be insurable and people could be rewarded for accepting occasional or regular water-related problems. New residents should be informed on the risks in the area and the measures they themselves can take to prevent, for instance, flooding. Furthermore, the social structure in the area should be enhanced. Social cohesion could turn the response to disturbances into a more collective effort and increase flexibility.

Early-warning and response mechanisms could limit the impacts of disturbances. Residents should be warned of impending floods, for instance by sending area-wide text messages. Smart flood controls could be activated in case of impending problems and sensors could warn when flood defences may start to fail. Effective disaster management and recovery plans for the area are needed as well. Counter-expertise and -advice should be included in project development to identify possible problems before disruptive events occur.

Urban planning could also contribute to limiting impacts. For instance, the road system could be designed to enhance the removal of water from the area in case of flooding (or ice in case of ice-drift), and to enhance wind flow through the area, providing ventilation. Trees, parks, 'green rooftops', and other vegetation could be introduced to enhance cooling. Housing design could also attempt to improve ventilation/cooling. Furthermore, careful selection of construction materials may counteract disturbances (e.g. materials that reduce the urban heat island effect) or enhance recovery (e.g. materials that are easy to repair). 
Flexible structures and infrastructure would provide a stabilising feedback as well. Participants mentioned floating and floatable ('amphibious') houses, flexible docks, and roads that compensate for inundation. Flexible flood defences (e.g. small scale 'flood beams' and large scale flexible storm surge barriers) could be closed when necessary, while not preventing access at other times. Critical facilities, such as the crisis management centre, could be made mobile.

\subsection{Omnivory}

Omnivory involves having several different ways of fulfilling one's needs; when one becomes unavailable, other ways can be used. It is similar to redundancy, but entails multiple different approaches that can be used alongside each other, rather than multiple copies of one approach. The area could diversify energy supply options, for instance by implementing small scale energy generation and energy/heat storage. These options could prevent blackouts should the normal power plants' energy production be reduced during prolonged heat and drought. Options for inland transportation of goods could be diversified. Goods could be transported by rail when inland shipping is hampered by low river levels (due to drought). Conversely, inland shipping ${ }^{7}$ could back up rail transport hampered by flooding. These ships should be available in diverse configurations in order to be useful in different situations. Multi-functionality can help as well. For instance, buildings could be designed to be useful for multiple functions. If parts of the area are flooded, functions could easily be relocated to other buildings in other parts of the area.

\subsection{High flux}

High flux allows for quick responses to threats and changes. One way to implement high flux would be to shorten the planning horizon for buildings, and urban planning in general. For instance, one could plan for houses to be replaced after 30 years rather than 50; thus ground level can be elevated/modified more quickly. This can be combined with a 'cradle-to-cradle' approach and the use of modular elements in buildings; building a "rebuildable city". If elements of constructions could be reused or deconstructed and later rebuilt, the area could be modified relatively quickly, and at lower costs, to accommodate changing conditions. Other suggestions included: quick notification of high tides, allowing residents and officials to take measures early on (high flux of information), and planning 'green areas' and other quickly-modifiable land-uses in areas where future changes may be required (high flux of land use).

\subsection{Flatness}

Flatness involves preventing the system from becoming top-heavy; overly hierarchical. In top-heavy systems, early-warning signals observed at the bottom reach higher levels too slowly due to long or complex/noisy lines. When decision-authority lies at these higher levels, decision-power and reaction-capacity are severely limited. In the context of social-ecological systems, this would involve overly complex procedures for decision making, bureaucracy, and a limited influence of local actors on policy. This would reduce the flexibility, slow the response to disturbances and compromise the adequacy of responses. Options can be divided into two groups. First, the population should be able and be allocated the competence and power to respond to possible problems. It should be made more self-reliant, self-sufficient, self-regulating, and self-organising. The government should leave room and provide capacity for residents to modify the area in order to limit damage and problems. One specific option that was mentioned was to grant neighbourhood directors authority on water safety. Second, policymaking should be made more participative and tailored to the local situation. Workshop participants typified this as "holistic governance" and "creating a clearly communicable safety-culture in which professionals and residents participate". A separate status for areas outside the dike defence zones might be useful.

\subsection{Buffering}

Buffering entails the ability to absorb disturbances to a certain extent. In the context of flooding hazards, certain (nonessential) low-lying places could be planned to serve as water retention areas for a limited period, until high water tides are reduced. The concept of 'water squares' is already used in Rotterdam's water policy plans. Parks, and underground storage areas and car-parks could be used as well. Other areas could be elevated, to house essential functions and to serve as flood refuge. The main roads leading into and out of the area could also be raised. This would allow them to be used during flooding, for instance for evacuations. Lining the road with pegs would indicate the road and allow it to be used during minor flooding.

Another form of buffering is to design buildings with non-essential and/or flooding-resistant functions on ground level. For example, living-quarters and ICT facilities should be moved to higher floors, while ground level could be used for parking. Some facilities (e.g. servers) could be placed outside the area. Water-proofing ground level (e.g. sealable windows/doors) and using materials that are resistant to water, heat, and ice-drift in buildings and infrastructure would help absorb disturbances. Having extra storage capacity and emergency supplies on hand, would help buffer against temporary isolation of the area.

In addition to buffering capacity against disrupting events, one could buffer against disrupting trends by leaving plenty of open spaces (parks, squares, etc.). These could change function relatively rapidly if the future situation would demand this, thus increasing the flexibility of the area's urban planning.

\footnotetext{
${ }^{7}$ Shipping is relevant assuming the port function will at least be partly maintained in the future.
} 


\subsection{Redundancy}

Redundancy involves having multiple instances of something available; when one fails, others can be used. This could involve having multiple routes (roads, ferry services, etc.) into and out of the area. Multiple routes to supply the area with electricity and to remove sewage should also be available. Multiple crisis-centres, in different locations, would be useful should one location become unavailable due to, for instance, flooding. Buildings could have multiple access levels; should the first floor be flooded, people could be evacuated from a higher floor. Vital functions (housing, hospitals, etc.) should have counterparts outside the area as well. These counterparts should be easy to reach and should have the capacity to accommodate a sudden increase in demand.

\subsection{Other options}

During the brainstorm using the resilience principles, participants suggested several options that, in retrospect, did not really fit the principles. One group of options focused on evacuation and refuge during floods. Homes should have evacuation plans, shallow draft boats should be available to evacuate people from the area, emergency exercises should be held regularly, and people should be able to find refuge in buildings as much as possible (reducing dependency on the state of the infrastructure - for example, if the roads were unable to be used as an evacuation route). While these options resemble the 'high flux' principle, they entail foresight, planning, and heightened activity when required, whereas high flux entails continuously high dynamics.

Furthermore, some options dealt with planning and management. The area should have clear - and clearly communicated contingency planning, strategies for managing risks, vulnerabilities, river and water, supplies and storage, et cetera. Participants suggested segmenting or categorising the area into sub-areas, depending on the vulnerabilities, and tailoring policy options to these sub-areas. Furthermore, the city should examine good practices elsewhere, use the available knowledge-infrastructure, and prevent trial-and-error with citizens.

Several other options focused on a flexible and more positive perception of water issues. These should be seen as a chance to create new ideas, rather than as a threat, and alliances could be made with companies who want to distinguish themselves on this issue.

\section{Discussion}

\subsection{Reflection on the resilience principles and comparison with the Vancouver study}

We used resilience principles derived from ecosystems and system dynamics and applied them as a tool to support creative thinking on adaptation of an urban delta. The principles are grounded in a solid knowledge base regarding how ecosystems behave under stress. However, for urban systems, other characteristics may be relevant (and currently overlooked). These principles need thus to be evaluated in this context of use and should be replaced or supplemented if other principles would better fit this purpose.

All principles proved applicable to urban systems. However, several suggested options had no clear relation to any of the principles used. Options related to 'positive thinking' regarding disturbances - thinking with the trends rather than against them - could be described as a type of (perceptional) flexibility in order to stimulate innovative thinking. It seems unlikely that including this as a separate resilience principle would result in a better inventory of adaptation options. Most of the 'other options' concerned management/planning and evacuations. This may require an additional principle.

In contrast to our approach, the Vancouver study [20] used ad-hoc ideas on what a resilient urban system implies. Although it is based on the urban situation, it may overlook relevant system-dynamical elements. A comparison may yield lessons.

The Vancouver study focuses on two characteristics: robustness to stress and adaptability/flexibility in response to changing conditions and objectives. These also feature in the original principles. For instance, buffering relates to robustness and omnivory to flexibility. Literature on adaptation principles suggest a third characteristic, in addition to the two above: increasing the rate of depreciation [49] or reducing the irreversible commitment of resources [50]. This relates to high flux. Options can be structural (e.g. physical measures) and non-structural (e.g. modifications to policy/management) [50]. However, Vancouver and this study differ in emphasis regarding the resulting policy suggestions: Vancouver emphasises spatial planning and management, while many options in this study are physical and other structural measures.

The Vancouver study notes careful planning, (adaptive) management, foresight and monitoring of local climate change impacts as strategies. As noted above, these appear in this study as well. They are similar, but not equal to high flux. Planning and foresight/research are important instruments of anticipatory adaptation [49], which is specific to human rather than natural systems. It is important that information from research/foresight reaches local practitioners [15,50]. The present principles may overlook options to enhance anticipatory responsiveness. Therefore, we suggest adding 'foresight, preparedness and planning practices' as resilience principle.

Related to planning, the Vancouver study interprets 'adaptability' as: flexibility (minor shifts in how systems function, space is used), convertibility (changes in use of land or buildings), and expandability (changes in quantity of space for particular uses). These could perhaps be interpreted as a system's structural 'elbowroom'. In this study, they are covered under omnivory and buffering. However, not all forms of convertibility are omnivory. Relocating existing functions to other spaces/buildings is (multiple locations to fulfil the function), but attracting/switching to new functions is not. As 'elbowroom' is highly important for resilience against disturbing trends, it can serve as additional principle. To prevent confusion with 'adaptive capacity', we suggest naming it 'flexible planning/design'. 
Finally, the Vancouver study discusses concepts such as compartmentalisation, modularisation, 'short loops', and shockresilient cells. These concern (but are broader than) distributed services and infrastructure (omnivory) and self-sufficiency (flatness). They provide a basis for coordinated response and recovery and can halt "the cascading of problems from one location or system to another" [20]. Compartmentalisation could be added as another principle.

\subsection{Reflection on the approach and results}

Participants considered resilience a useful concept for local climate adaptation and were positive on the way it was operationalised. ${ }^{8}$ While the resilience principles seem difficult concepts to grasp, workshop participants had no difficulty working with them. Combined with a short description and practical examples, they were intelligible and facilitated generation of options. The combination of scientists and regional practitioners in the workshop was useful, but (in this case) perhaps not critical because the practitioners were already experienced and knowledgeable on climate impacts. The scientists were important for the process. Particularly, one scientist seeded the group with examples on resilience-based adaptation in other regions, and the social scientists provided focus on the societal effects/implications of impacts.

A drawback of our approach is that it only generates a list of options without offering means to choose among them. Feasibility of the options has not been evaluated. Some options can be considered 'no-regret', such as enhancing interaction with residents and keeping criticality/vulnerability in mind in spatial planning (e.g. hospitals/care-homes on high ground, squares/parks in lower parts). For additional options, several suggestions can be made. Firstly, it is difficult to assess their relative contributions to resilience and to limiting climate impacts in general, preventing cost-benefit analysis and comparison with other adaptation approaches. It may be possible to assess the contribution to individual resilience principles using multiple (semi-)quantitative and qualitative indicators. Secondly, it is important to assess the possible (negative and positive) side-effects of options and strategies [7]. For instance, disturbance-proof materials may increase the cost of living in the area, which would have implications for socio-economic policies. They may also reduce the potential for high flux. One should assess which options are complementary and which ones conflict [49], among resilience-options as well as between resilience-options and options of other approaches (e.g., raising ground levels (predictand-prevent) reduces the usefulness of extensive water retention areas (resilience)). Similarly, it is important to assess possible conflicts and synergies with mitigation (e.g. air conditioning (homeostasis) would increase energy consumption). Thirdly, the time horizons of options will need to be considered (cf. $[49,50]$ ). Some decisions have long time horizons and cannot be easily changed later. An exercise in this study suggested that housing- and port-related functions have long horizons, while commercial and tourism functions have shorter ones. The timing of climate impacts and other developments/trends may also call for certain options to be taken before a certain point. Particularly, decisions with large spatial claims would need to be taken soon, or the limited space may already be claimed for other (long-term) uses. Concluding the above, an assessment of the costs, co-benefits, and tradeoffs of options will be useful for determining the timing, priorities, and level of ambition for resilience-oriented adaptation.

\subsection{Resilience and climate change adaptation under uncertainty}

A resilience approach to a climate change adaptation should be able to limit impacts even if magnitude and direction are uncertain or unknown [4]. Policy-relevant uncertainties can include statistical uncertainties, scenario uncertainties, or recognised ignorance [51].

Regarding statistical uncertainties, strategies should be able to deal with a continuous range of conditions, rather than only the 'average'. For instance, they should not only be viable for 'average' temperatures, but also for unusually warm/cold situations. Buffering and homeostasis reduce the impact of disturbances that vary in magnitude, and, depending on their extent, nullify that of more frequent events. When impacts do occur, principles that enhance the responsiveness (e.g. high flux, preparedness/ planning) or allow for failure (e.g. omnivory, redundancy) will remain beneficial. Thus, resilient systems can cope with statistical uncertainty.

Scenario uncertainty stems from limited predictability of the future. Scenarios are plausible future developments of a system and/or its driving forces. All principles would limit the effect of disturbances under many scenarios. Some principles however are particularly useful in allowing the system to adjust to the trends. Flatness and high flux would enhance the effectiveness and speed of adaptation. Foresight and preparedness/planning and flexible planning/design further assist in both anticipatory and reactive adaptation to the way the system and disturbances may or will evolve. Thus, resilient systems can cope with scenario uncertainty.

Wildcards ('imaginable surprise scenarios') can be used to assess whether systems can cope with recognised ignorance. They can be divided into three types: (type-1) extreme forms of expected trends, (type-2) opposites of expected trends, and (type-3) completely new issues. Options can be expected to remain beneficial under type- 1 wildcards. Under type- 2 wildcards, many options will continue to be beneficial. Those that enhance flexibility and responsiveness can be expected to perform quite well. Some options, such as disturbance-proof materials or building-designs, could be no longer beneficial (though not necessarily detrimental) if a disturbance develops in an opposite way. It could be prudent to take the possibility of opposite impacts into account when designing such impact-specific measures. Relatively few options suggested by participants (see Section 5) would protect against type-3 wildcards, such as port malaria incidents. Monitoring would be helpful against such wildcards. However, in

\footnotetext{
8 Some participants did question the usefulness of the group model building exercise; partly due to the limited time available and switching between two software packages. It did however provide useful insights into participants' lines of reasoning regarding impacts. It could be usefully streamlined by developing an initial conceptual model with experts, then having it critiqued by practitioners.
} 
the case of malaria incidents, monitoring may fail due to misdiagnosis, and would not prevent possible public unrest following incidents. Options that could be beneficial include increased interaction between scientists and locals (medical professionals, citizens, officials) and shortening communication chains. This would involve pre-emptive education (e.g. informing general practitioners of the possibility of port malaria incidents), taking into account observations by the local population (including general practitioners) in monitoring programs, contingency planning, and adequate public information supply in the event of incidents. Emerging and unexpected issues should specifically be taken into account. Regular reassessment and updating of existing policies could also be useful to take such new knowledge into account [52]. Such flatness and foresight and preparedness/planning options would increase resilience against type-3 wildcards. Concluding, resilient systems can cope with recognised ignorance.

\subsection{Resilience versus other adaptation approaches}

Traditionally, Dutch water management focuses on predictive approaches, reducing the probability of occurrence of disturbances (e.g. building/raising dikes), by designing for a desired safety level (e.g. a design flood level of 1/10,000 yr). This probability-oriented risk approach ('prevention principle') can cope well with statistical uncertainty [4], in a cost-efficient manner. Using predictive modelling, one can cope with scenario uncertainty, often by dimensioning to the maximum likely scenario. Potential downsides are the risk of overinvestment, limited flexibility, and increased vulnerability if the projection turns out to be too optimistic. Flexible approaches such as anticipating design can be helpful here. The potential for coping with surprises is very limited. Overdimensioning adaptation measures to cope with type- 1 surprises would entail basing policy on an assumed worst-worst case scenario, requiring huge investments and highly invasive measures, and strongly enhancing vulnerability against a failed projection. Such approaches may also fail (no or negative effect) under type-2 surprises. Obviously, predictive approaches do not protect against type-3 surprises at all.

Resilience could therefore complement other approaches, such as robust decision making [53] and predict-and-prevent oriented approaches, to arrive at an overall strategy that limits probabilities, impacts, and exposure. For urban deltas this is particularly salient, because the large concentrations of population and capital imply that risks remain high even when probabilities are reduced. This holds even truer for areas where conventional probability-reducing measures (e.g. dikes) are not feasible or desirable, and for disturbances whose probability cannot be controlled through adaptation (e.g. the occurrence of heat waves).

Participants noted that current water safety regulations are rigid and top-down, imposed by national government and regional water boards. However, local institutions and populations have the knowledge of the local conditions that are central to climaterelated risks, and need to be enabled to evolve their own response strategies and be granted access to the information and systems that will able them to respond [54]. Resilience was framed as an approach that would be more flexible, less regulation-intensive, more focused on 'growing with the trends' and better suited to the local circumstances. They considered it a useful approach for local adaptation. It would benefit resilience if local decision makers would receive more room to tailor policies to their own situations. On a lower scale, resilience would be dependent on the self-organization, self-regulation, and self-reliance of the population. It also presents a possibility to increase public participation, potentially increasing support for the adaptation policy. Increasing their responsibilities would demand both suitable formal frameworks and a different mentality among the population, as well as investments in increasing their competence. As participants noted, attitudes such as "the government will solve it for us" and a "claim-culture" (regarding flooding damage) would not be suitable.

\section{Conclusions}

This paper has operationalized 'resilience' as an approach to climate change adaptation under uncertainty, by means of a casestudy in the areas outside the dike defence zones in Rotterdam, the Netherlands.

Climate change is expected to impact this urban coastal delta in numerous, and often uncertain, ways. Sea level rise is expected to be a major disturbance, particularly if combined with possible changes in storm surge conditions. These can increase the flooding frequencies and risks in these already flood-prone neighbourhoods. Other disturbances include increased temperature and decreased summer river discharge. These could result in problems for electricity supply, drinking water supply, water quality, and air quality. Relevant wildcards for the area include: thermohaline circulation collapse, port freezing events, port malaria incidents, modified German water safety policy, enduring heat and drought, extreme storm, and failure of the Maeslantkering storm surge barrier during an extreme storm. Participants framed the impacts of disturbances as issues of societal disruption, property damage, and attractiveness and image of the area.

Using six resilience principles, various options were generated to increase resilience. Homeostasis can be enhanced by creating greater clarity on responsibilities, early-warning, response, and feedback mechanisms, spatial planning strategies that reduce impacts or enhance recovery, and flexible structures, infrastructure and flood defences. Omnivory can be created by diversifying and distributing electricity generation, diversifying transportation options, and creating multi-functional spaces and buildings. High flux can be implemented by reducing planning horizons, possibly combined with cradle-to-cradle approaches, and planning easy-to-modify land-uses in areas that may need quick modification. Flatness involves enabling local populations to self-respond to disturbances (self-sufficiency, self-regulation, and self-organization), and increasing public participation in climate adaptation. Buffering can be enhanced by creating disturbance-proofed, low-elevation spaces (e.g. squares and parks) and ground-floors, with non-essential functions. These absorb the first impacts of disturbances; essential functions are moved to higher elevations. Leaving 
plenty of open space would enhance buffer-capacity against future trends. Redundancy could be implemented by creating multiple routes for electricity supply and transportation and multiple access levels for buildings, and by duplicating vital functions.

The resilience principles (plus practical examples) succeeded in making resilience sufficiently operational for local actors to translate the concept into concrete options. For urban climate adaptation the original six principles can be supplemented with: (a) foresight, preparedness, and planning (including monitoring, management and contingency plans, evacuation exercises, and specific attention for communication and emerging/unexpected issues), (b) compartmentalisation, and (c) flexible planning/ design. Resilience provides a useful approach that is robust to the many uncertainties that decision makers face regarding climate change adaptation, including to surprises, and therefore has added value for climate change adaptation. Local actors framed resilience as a highly flexible approach that is adaptive to both the changing environment and to the local situation and needs. Such flexibility would however require suitable formal frameworks (legal and governmental) and a different, more proactive mentality among the local population.

\section{Acknowledgements}

This study was funded by Dutch national research programme ‘Climate changes Spatial Planning', project IC10. We would like to thank Joop de Boer (VU University Amsterdam), Karen Buchanan, Rien Kolkman, and Anne van der Veen (University of Twente) for fruitful collaboration. We would like to thank Pieter de Greef (Rotterdam dS $+\mathrm{V}$ ) for contributing to this study as our liaison in Rotterdam. The Netherlands Environmental Assessment Agency is thanked for funding the 'scoping study' and follow-up casestudies on uncertainty and climate change adaptation, which provided the conceptual framework and context for this study.

We would like to thank the following persons for taking part in the interviews and/or workshop: Pieter de Greef, Walter de Vries, Luit de Haas, Wim Egberts, Tjade Tijsseling (Rotterdam dS + V), Joost Lankester (Rotterdam GW), Dick van den Bergh (Province of Zuid-Holland), Geert Groen (KNMI), Judith Klostermann (Wageningen University), and Joop de Boer. Pieter van Eeden (Cadre BV) and Frank van Kouwen (Quasta BV) are thanked for facilitating the workshop. Wim Turkenburg and two anonymous referees are acknowledged for comments and suggestions.

\section{References}

[1] IPCC, Climate Change, Impacts, adaptation and vulnerability. contribution of working group II to the fourth assessment report of the intergovernmental panel on climate change, in: M.L. Parry, O.F. Canziani, J.P. Palutikof, P.J. van der Linden, C.E. Hanson (Eds.), Intergovernmental Panel on Climate Change (IPCC), Cambridge University Press, New York, 2007.

[2] S.J. Smith, T.M.L. Wigley, N. Nakicenovic, S.C.B. Raper, Climate implications of greenhouse gas emissions scenarios, Technol. Forecast. Soc. Change 65 (2) (2000) 195-204

[3] Grübler, N. Nakicenovic, K. Riahi, F. Wagner, G. Fischer, I. Keppo, M. Obersteiner, B. O'Neill, S. Rao, F. Tubiello, Integrated assessment of uncertainties in greenhouse gas emissions and their mitigation: introduction and overview, Technol. Forecast. Soc. Change 74 (7) (2007) 873-886.

[4] S. Dessai, J.P. van der Sluijs, Uncertainty and Climate Change Adaptation - A Scoping Study, Copernicus Institute for Sustainable Development and Innovation, Utrecht University, Utrecht, 2007.

[5] J. Mathijssen, A. Petersen, P. Besseling, A. Rahman, H. Don (Eds.), Dealing with Uncertainty in Policymaking, PBL publication 550032011, Netherlands Bureau for Economic Policy Analysis (CPB), Netherlands Environmental Assessment Agency (PBL), and RAND Europe, The Hague/Bilthoven/Leiden, 2008.

[6] J.A. Wardekker, J.P. van der Sluijs, P.H.M. Janssen, P. Kloprogge, A.C. Petersen, Uncertainty communication in environmental assessments: views from the Dutch science-policy interface, Environ. Sci. Policy 11 (7) (2008) 627-641.

[7] S. Hallegatte, Strategies to adapt to an uncertain climate change, Glob. Environ. Change 19 (2) (2009) $240-247$.

[8] C.S. Holling, Resilience and stability of ecological systems, Annu. Rev. Ecol. Systemat. 4 (1973) 1-23.

[9] C. Folke, Resilience: The emergence of a perspective for social-ecological systems analyses, Glob. Environ. Change 16 (2006) $253-267$.

[10] W.N. Adger, Social and ecological resilience: are they related? Prog. Hum. Geogr. 24 (3) (2000) 347-364.

[11] S. Carpenter, B. Walker, J.M. Anderies, N. Abel, From metaphor to measurement: resilience of what to what? Ecosystems 4 (2001) $765-781$.

[12] R.J.T. Klein, R.J. Nicholls, F. Thomalla, Resilience to natural hazards: how useful is this concept? Global Environ. Change B Environ. Hazards 5 (1-2) (2003-2004) $35-45$.

[13] B. Walker, C.S. Holling, S.R. Carpenter, A. Kinzig, Resilience, adaptability and transformability in social-ecological systems, Ecol. Soc. 9 (2) (2004) 5-13.

[14] Resilience Alliance, Resilience, The Resilience Alliance, 2008. URL (consulted September 2008): http://www.resalliance.org/576.php.

[15] J. Barnett, Adapting to climate change in Pacific Island countries: the problem of uncertainty, World Dev. 29 (2001) 977-993.

[16] A.B. Wildavsky, Searching for Safety, Transaction Publishers, New Brunswick, 1988.

[17] F. Villa, H. McLeod, Environmental vulnerability indicators for environmental planning and decision-making: guidelines and applications, Environ. Manag. 29 (2002) 335-348

[18] K.M. de Bruijn, Resilience and flood risk management, Water Policy 6 (2004) 53-66.

[19] K.M. de Bruijn, Resilience indicators for flood risk management systems of lowland rivers, Int. J. River Basin Manag. 2 (3) (2004) 199-210.

[20] Sheltair Group, Climate Change Impacts and Adaptation Strategies for Urban Systems in Greater Vancouver, Volume 1, The Sheltair Group, Vancouver, 2003. Available via: http://web.archive.org/web/20060626205505/http://www.sheltair.com/library/VOL+1+citiesplus +Climate+Chg +I+and+A+Strategies + by +Urban +System + for + Gtr+Van+Aug +2003.pdf.

[21] J. de Boer, The role of prevention-oriented attitudes towards nature in people's judgment of new applications of genomics techniques in soil ecology, Public Underst. Sci. (in press), doi:10.1177/0963662509342473.

[22] J. de Boer, J.A. Wardekker, J.P. van der Sluijs, Frame-based guide to situated decision-making on climate change, Paper presented at the IARU International Scientific Congress on Climate Change: Global Risks, Challenges and Decisions, Copenhagen, March 122009.

[23] K.E.F. Watt, P.P. Craig, System stability principles, Syst. Res. 3 (1986) 191-201.

[24] A. de Jong, Veerkracht als strategie voor klimaatadaptatie onder onzekerheid: Onderzoek aan de hand van de casus 'Het buitendijks gebied van gemeente Rotterdam', Copernicus Institute for Sustainable Development and Innovation, Utrecht University, Utrecht, 2008.

[25] J.A. Wardekker, A. de Jong, J.P. van der Sluijs, Veerkrachtig Rotterdam: klimaatverandering als uitdaging, Workshopverslag, Copernicus Institute for Sustainable Development and Innovation, Utrecht University, Utrecht, 2008.

[26] J.A.M. Vennix, Group Model Building, John Wiley \& Sons, Chichester, 1996.

[27] J.A.M. Vennix, Group model-building: tackling messy problems, Syst. Dyn. Rev. (4) (1999) 379-401.

[28] A.L. Delbecq, A.H. van der Ven, D.H. Gustafson, Group Techniques for Program Planning: A Guide to Nominal Group and Delphi Processes, Scott, Foresman \& Co, Brighton, 1975. 
[29] E. Turban, J.E. Aronson, Decision Support Systems and Intelligent Systems, 5th editionPrentice-Hall, Upper Saddle River, 1998.

[30] GroupSystems, GroupSystems Workgroup Edition \& Professional Suite, Version 3.4, GroupSystems, 2002.

[31] F.A. van Kouwen, The Quasta approach: exploring new pathways to improve the use of knowledge in sustainability challenges, PhD thesis, Utrecht University, Utrecht, 2007

[32] F.A. van Kouwen, C. Dieperink, P.P. Schot, M.J. Wassen, Computer-supported cognitive mapping for participatory problem structuring, Environ. Plann. A 41 (1) (2009) 63-81.

[33] Rotterdam.dS + V, Stadsvisie Rotterdam: Ruimtelijke ontwikkelingsstrategie 2030, Department for Urban Planning and Housing (dS + V), Municipality of Rotterdam, Rotterdam, 2007.

[34] KNMI, Climate in the 21st Century: Four Scenarios for the Netherlands, Royal Netherlands Meteorological Institute (KNMI), De Bilt, 2006.

[35] B. van den Hurk, A. Klein Tank, G. Lenderink, A. van Ulden, G.J. van Oldenborgh, C. Katsman, H. van den Brink, F. Keller, J. Bessembinder, G. Burgers, G. Komen, W. Hazeleger, S. Drijfhout, KNMI Climate Change Scenarios 2006 for the Netherlands, KNMI Scientific Report WR 2006-01, Royal Netherlands Meteorological Institute (KNMI), De Bilt, 2006.

[36] B. van den Hurk, A.K. Tank, G. Lenderink, A. van Ulden, G.J. van Oldenborgh, C. Katsman, H. van den Brink, F. Keller, J. Bessembinder, G. Burgers, G. Komen, W. Hazeleger, S. Drijfhout, New climate change scenarios for the Netherlands, Water Sci. Technol. 56 (4) (2007) 27-33.

[37] K. Peijs, Toetsen op veiligheid Maeslantkering: stand van zaken, Letter of the Minister of V\&W to The Dutch House of Representatives, Letter no. 37349 , 16 October 2006, Ministry of Transport, Public Works and Water Management (V\&W), The Hague, 2006.

[38] J. Kwadijk, A. Jeuken, H. van Waveren, De klimaatbestendigheid van Nederland Waterland: Verkenning van knikpunten in beheer en beleid voor het hoofdwatersysteem, Deltares, Delft, 2008.

[39] Rotterdam.GW, Zeespiegelstijging: analyse van de risico's voor het stadshavengebied Rotterdam, Rotterdam Public Works Department (GW), Municipality of Rotterdam, Rotterdam, 2005.

[40] RWS, Waternormalen, National water level and discharge database, Directorate-General for Public Works and Water Management (RWS), Ministry of Transport, Public Works and Water Management, The Hague, 2009 URL (consulted January 2009): http://www.waternormalen.nl/.

[41] J.A. Lowe, J.M. Gregory, The effects of climate change on storm surges around the United Kingdom, Philos. Trans. R. Soc. A-Math. Phys. Eng. Sci. 363 (2003) 1313-1328.

[42] Rotterdam, Hollandse Delta, Schieland en de Krimpenerwaard, Rotterdam Waterstad 2035, in: P. de Greef (Ed.), Municipality of Rotterdam, Water Board Hollandse Delta, and Water Board Schieland en de Krimpenerwaard, Episode Publishers, Rotterdam, 2005.

[43] VROM, Startnotitie Randstad 2040, Ministry of Housing, Spatial Planning and the Environment (VROM), The Hague, 2007.

[44] R. van der Wouden, R. Kuiper, C. Eijgenraam, Ex antetoets Startnotitie Randstad 2040, RPB policy advice no. 8, Netherlands Institute for Spatial Research (RPB), Netherlands Environmental Assessment Agency (MNP), and Netherlands Bureau for Economic Policy Analysis (CPB), The Hague/Bilthoven, 2008.

[45] Deltacommissie, Samen werken met water - Een land dat leeft, bouwt aan zijn toekomst. Bevindingen van de Delta4commissie 2008, Deltacommissie, Rotterdam, 2008.

[46] MNP, Nederland Later: Tweede Duurzaamheidsverkenning, deel Fysieke leefomgeving Nederland, Netherlands Environmental Assessment Agency (MNP), Bilthoven, 2007

[47] T. Kuhlbrodt, S. Rahmstorf, K. Zickfeld, F.B. Vikebø, S. Sundby, M. Hofmann, P.M. Link, A. Bondeau, W. Cramer, C. Jaeger, An integrated assessment of changes in the thermohaline circulation, Clim. Change 96 (4) (2009) 489-537.

[48] M. Isaäcson, Airport malaria: a review, Bull. World Health Organ. 67 (6) (1989) 737-743.

[49] S. Fankhauser, J.B. Smith, R.S.J. Tol, Weathering climate change: some simple rules to guide adaptation decisions, Ecol. Econ. 30 (1999) 67-78.

[50] K.D. Frederick, D.C. Major, E.Z. Stakhiv, Water resources planning principles and evaluation criteria for climate change: summary and conclusions, Clim. Change 37 (1997) 291-313.

[51] W.E. Walker, P. Harremoës, J. Rotmans, J.P. van der Sluijs, M.B.A. van Asselt, P. Janssen, M.P. Krayer von Krauss, Defining uncertainty: a conceptual basis for uncertainty management in model-based decision support, Integrated Assess. 4 (1) (2003) 5-17.

[52] L.E. McCray, K.A. Oye, A.C. Petersen, Planned adaptation in risk regulation: An initial survey of US environmental, health, and safety regulation, Technol. Forecast. Soc. Change 77 (6) (2010) 951-959 (this issue).

[53] R.J. Lempert, D.G. Groves, Identifying and evaluating robust adaptive policy responses to climate change for water management agencies in the American West, Technol. Forecast. Soc. Change 77 (6) (2010) 960-974 (this issue).

[54] M. Moench, Responding to climate and other change processes in complex contexts: Challenges facing development of adaptive policy frameworks in the Ganga Basin, Technol. Forecast. Soc. Change 77 (6) (2010) 975-986 (this issue).

Arjan Wardekker is a researcher at Utrecht University. His interests include dealing with risks and uncertainties in environmental policymaking and advice, particularly on issues such as climate change and air quality, risk/uncertainty perception and communication, and environmental ethics.

Arie de Jong is a researcher at Utrecht University. He explores the concept of resilience by operationalising it both qualitatively and quantitatively. Furthermore, his interests include climate change adaptation strategies and post normal science and practice.

Joost Knoop is a senior policy researcher at the Netherlands Environmental Assessment Agency. The water and climate issue at the national scale, including adaptation strategies and dealing with uncertainties are at present his main research topics.

Jeroen van der Sluijs is a senior researcher and assistant professor at Utrecht University and visiting professor at the Centre of Economics and Ethics for the Environment and Development (C3ED), University of Versailles Saint-Quentin-en-Yvelines, France. He has published strategies to cope with uncertainty in science for policy, codes for good modelling practice, uncertainty communication and the precautionary principle. 